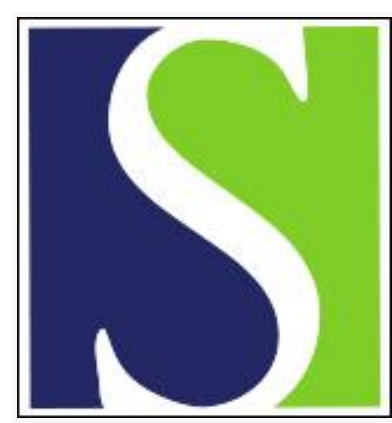

Scand J Work Environ Health 2001;27(6):402-412

https://doi.org/10.5271/sjweh.633

Issue date: Dec 2001

Associations of lead biomarkers and delta-aminolevulinic acid dehydratase and vitamin $D$ receptor genotypes with hematopoietic outcomes in Korean lead workers

by Lee S-S, Lee B-K, Lee G-S, Stewart WF, Simon D, Kelsey K, Todd AC, Schwartz BS

Affiliation: Institute of Industrial Medicine, Soonchunhyang University, Chonan, Korea.

Key terms: bone lead; chelatable lead; cross-sectional study; delta-aminolevulinic acid dehydratase; dimercaptosuccinic acid; genetic polymorphisms; hematopoietic outcome; hematopoietic system; Korea; lead biomarker; lead worker; vitamin D receptor genotype

This article in PubMed: www.ncbi.nlm.nih.gov/pubmed/11800328 


\title{
Associations of lead biomarkers and delta-aminolevulinic acid dehydratase and vitamin D receptor genotypes with hematopoietic outcomes in Korean lead workers
}

\author{
by Sung-Soo Lee, MD, ${ }^{1}$ Byung-Kook Lee, MD, ${ }^{1}$ Gap-Soo Lee, MD, ${ }^{1}$ Walter F Stewart, PhD, ${ }^{2,}{ }^{3}$ David \\ Simon, MS, ${ }^{3}$ Karl Kelsey, MD, ${ }^{4}$ Andrew C Todd, PhD, ${ }^{5}$ Brian S Schwartz, MD ${ }^{2,3,6}$
}

\begin{abstract}
Lee S-S, Lee B-K, Lee G-S, Stewart WF, Simon D, Kelsey K, Todd AC, Schwartz BS. Associations of lead biomarkers and delta-aminolevulinic acid dehydratase and vitamin $D$ receptor genotypes with hematopoietic outcomes in Korean lead workers. Scand J Work Environ Health 2001;27(6):402-412.
\end{abstract}

\begin{abstract}
Objectives This study compares and contrasts associations of dimercaptosuccinic acid (DMSA)-chelatable lead, tibia lead, and blood lead with five hematopoietic outcomes and evaluates the effect modification of these relations by polymorphisms in the delta-aminolevulinic acid dehydratase (ALAD) and vitamin D receptor (VDR) genes.

Methods A cross-sectional study of 798 lead workers and 135 unexposed referents was performed.

Results The DMSA-chelatable lead, tibia lead, and blood lead levels ranged in the lead $(\mathrm{Pb})$ workers from 4.8 to $2103 \mathrm{~g},-7$ to $338 \mathrm{~g} \mathrm{~Pb} / \mathrm{g}$ bone mineral, and 4 to $86 \mathrm{~g} / \mathrm{dl}$, respectively. The mean of the hemoglobin, hematocrit, zinc protoporphyrin (ZPP), and urinary (ALAU) and plasma (ALAP) delta-aminolevulinic acid levels of the lead workers were 14.2 (SD 1.4) g/dl, 42.4 (SD 4.4)\%, 80.2 (SD 63.5) g/dl, 2.1 (SD 3.7) mg/l, and 17.7 (20.6) $\mathrm{g} / \mathrm{ml}$, respectively. After adjustment for the covariates, tibia lead was associated with all five hematopoietic outcomes, while blood lead and DMSA-chelatable lead were associated only with ZPP, ALAP, and ALAU. A comparison of the regression coefficients, total model adjusted $\mathrm{R}^{2}$ values, and delta $\mathrm{R}^{2}$ values revealed that blood lead was the best predictor of ZPP, ALAP, and ALAU. Only tibia lead was significantly associated with hemoglobin and hematocrit levels, but the additional variance explained by tibia lead was $(\leq 1 \%)$. No clear effect modification of the relations between the lead biomarkers and hematopoietic outcomes studied was caused by ALAD or VDR genotype.
\end{abstract}

Conclusions Lead must have a chronic, cumulative effect on hemoglobin and hematocrit levels, and any speculated mechanism cannot merely involve short-term plasma or target organ lead levels.

Key terms bone lead, chelatable lead, cross-sectional study, dimercaptosuccinic acid, genetic polymorphisms, hematopoietic system.

Lead absorption is known to influence the hematopoietic system, for example, through increased destruction of erythrocytes, interference with the normal production of erythrocytes, and the inhibition of heme synthesis (1-
4). In the heme synthesis pathway, lead inhibits the second enzyme, cytosolic delta-aminolevulinic acid dehydratase (ALAD), which catalyzes the condensation of two molecules of aminolevulinic acid to form

Institute of Industrial Medicine, Soonchunhyang University, Chonan, Korea.

Division of Occupational and Environmental Health, Department of Environmental Health Sciences, Johns Hopkins Bloomberg School of Public Health, Baltimore, Maryland, United States.

Department of Epidemiology, Johns Hopkins Bloomberg School of Public Health, Baltimore, Maryland, United States. Department of Cancer Cell Biology, Harvard School of Public Health, Boston, Massachusetts, United States.

Department of Community and Preventive Medicine, Mount Sinai Medical Center, New York, New York, United States.

Reprint requests to: Dr Brian S Schwartz, Division of Occupational and Environmental Health, Johns Hopkins Bloomberg School of Public Health, Room 7041, 615 North Wolfe Street, Baltimore, MD, 21205, USA. [E-mail: bschwart@jhsph.edu] 
porphobilinogen $(5,6)$. Decreased ALAD activity results in increases of delta-aminolevulinic acid in urine (ALAU) and plasma (ALAP) $(7,8)$. Lead also interferes with the formation of heme from protoporphyrin IX through both the inhibition of the mitochondrial enzyme ferrochelatase and possibly reduced transport of bivalent iron into mitochondria because of the inhibited reduction of trivalent iron by lead exposure $(7,9-11)$. The resulting accumulation of zinc protoporphyrin (ZPP) in erythrocytes is a useful biomarker of lead-induced heme synthesis inhibition $(7,12)$.

Prior studies have focused mainly on the associations between blood lead levels and hematopoietic outcomes (13-18), and they have demonstrated significant interindividual variation. Fewer studies have utilized measures of chelatable lead, a measure of bioavailable lead burden, and tibia lead, a measure of cumulative lead dose $(19,20)$. To explore further the different kinetic pools of lead, to generate hypotheses regarding acute and cumulative effects, and to begin to understand this variation in response, we compared and contrasted dimercaptosuccinic acid (DMSA)-chelatable lead, tibia lead, and blood lead in the prediction of hematopoietic outcomes and evaluated the effect modification by two polymorphic genes [ALAD and vitamin D receptor (VDR)] known to modify the toxicokinetics of lead (8, $12,20)$. It is important to determine whether these two polymorphic genes, which have been reported to modify blood lead, chelatable lead, and tibia lead levels, also modify the effects of lead on health outcomes such as those of the hematopoietic system, since the observation of genetic effect modification allows inferences about the mechanism of lead-related health effects. Herein, we report associations of these three lead biomarkers with five hematopoietic outcomes (hemoglobin, hematocrit, ALAP, ALAU, ZPP) and the effect modification by ALAD and VDR in a cross-sectional analysis of 798 Korean lead workers and 135 referents without occupational lead exposure.

\section{Subjects and methods}

\section{Study population}

The subjects were drawn from a 3-year longitudinal study of the health effects of inorganic lead exposure, as previously described (21-23). Cross-sectional data from the first year of the study, on 798 lead workers from 26 different lead-using factories and 135 unexposed referents from an air conditioner assembly plant and the Soonchunhyang University, were used. Participation was voluntary, and all the subjects provided their written, informed consent. The study protocol was ap- proved by Institutional Review Boards at the Soonchunhyang University School of Medicine and the Johns Hopkins Bloomberg School of Public Health.

\section{Data collection}

The data collection methods have been previously described (21-23). In brief, the subjects completed a standardized questionnaire on demographics, medical history, and occupational history; underwent phlebotomy for the determination of blood lead, ZPP, and ALAP; had tibia lead measured by X-ray fluorescence (XRF); provided a spot urine specimen for the determination of ALAU; and completed a 4-hour urine collection after the oral administration of DMSA $(10 \mathrm{mg} / \mathrm{kg}$ ) (the lead workers only).

\section{Laboratory methods}

Tibia lead was determined with a 30 -minute measurement at the left mid-tibia shaft using ${ }^{109}$ cadmium-induced K-shell X-ray fluorescence, as previously described (24-26). For tibia lead the unit of measurement was micrograms of lead per gram of bone mineral (hereafter referred to as $\mu \mathrm{g} / \mathrm{g}$ ) (25). X-ray fluorescence can provide negative point estimates of bone lead concentrations that are very low; however, all point estimates were retained in the statistical analysis because this method minimizes bias and does not require data to be censored (19, 21-23). Blood lead levels were analyzed with a flameless atomic absorption spectrophotometer (Hitachi 8100, Hitachi Ltd. Instruments, Tokyo, Japan) with the standard addition method of the National Institute of Occupational Safety and Health (27) at the Institute of Industrial Medicine, Soonchunhyang University, in the Republic of Korea, as previously described (21).

DMSA-chelatable lead was determined by measuring 4-hour urinary lead excretion after the oral administration of DMSA $(10 \mathrm{mg} / \mathrm{kg})(28)$. The urine lead levels were analyzed in the laboratories of the Wadsworth Center at the New York State Department of Health. The urinary lead concentrations were measured by electrothermal atomization atomic absorption spectrometry (Perkin-Elmer 4100ZL, United States) (29). Hemoglobin was determined using the cyanmethemoglobin method (Beckman Coulter Inc, model Ac-T 8, United States), and hematocrit was measured using the capillary centrifugation method (30). ZPP was measured by a hematofluorometer (Aviv, United States) (31). The ALAU and ALAP levels were determined according to the method of Tomokuni et al (32). Creatinine in urine was analyzed by the Sigma kit (St. Louis, Missouri, United States) (33). ALAD and VDR genotyping were completed for 798 exposed subjects and 795 referents by previously described methods (34-37). 


\section{Statistical analysis}

The two main goals of the analysis were (i) to compare and contrast three different lead biomarkers (DMSAchelatable lead, tibia lead, blood lead) in their associations with five hematopoietic outcome variables (hemoglobin, hematocrit, ZPP, ALAU, ALAP) and (ii) to determine whether ALAD or VDR genotype modified the relations between the lead biomarkers and the hematopoietic outcomes. Statistical analysis was completed using statistical software programs of the SAS Institute Inc (Cary, North Carolina, United States).

First, unadjusted (crude) means of the hematopoietic outcomes (ie, by exposed versus reference status or by genotype) were compared; P-values for testing the equivalence between the unadjusted means were calculated using Student's t-test, after ln-transformation as appropriate. Next, linear regression was used to model the five hematopoietic outcomes separately while controlling for confounding variables. The associations between the lead dose measures and the genetic factors were evaluated for the lead workers only. The lead biomarkers were evaluated as predictors of hematopoietic outcomes in separate models to avoid problems of overcontrol and multicolinearity. A forward selection method was used as a framework for the model selection. Before the regression modeling, the distributions of the five outcome variables were examined, and after the regression modeling, the distributions of the residuals and residual versus residual plots were examined. The distributions of ZPP, ALAU, and ALAP were skewed, and therefore these variables were $1 n$-transformed before the final regression modeling. In addition, four extreme values for DMSA-chelatable lead were identified and removed from the analysis.

A covariate was retained in the final regression models if it was either a significant predictor of the hematopoietic outcomes or if it was a confounder of the relation between the predictor variables and hematopoietic outcomes. Nonlinear relations were evaluated by the inclusion of quadratic terms (after centering) for the lead dose measures. The covariates examined in linear regression models included age, gender, body mass index (BMI, weight in kilograms divided by the square of height in meters; only in models for hemoglobin and hematocrit), job duration, and tobacco and alcohol consumption (divided into quartiles for each, by cumulative lifetime consumption in pack-years for tobacco or years-drinks/week for alcohol, where one drink was one glass of beer or wine or one shot of distilled spirits). Job duration was evaluated because its control was observed to make associations of tibia lead levels with neurobehavioral test score decrements more apparent in prior analyses (21).

With the use of the final regression models, the relations between the hematopoietic outcomes and the lead biomarkers were graphically displayed using partial residual (residual versus residual) plots. For each plot, two lines were overlaid: the regression line and a line determined by a scatter plot smoothing method. The scatter plot smoothing method calculates a locally weighted least-squares estimate for each point in the scatter plot (38). The function "lowess" of the S-plus statistical software program was used to produce the plot (Data Analysis Products Division of MathSoft, Seattle, Washington, United States). After examining the residual-residual plots, we found that the regression models for hematocrit were highly influenced by 15 subjects with hematocrit values over $52 \%$. Because of concern that these values could be pathological for reasons unrelated to lead or the other variables controlled in the regression models, the models with hematocrit have been presented without these subjects included. The residual-residual plots also suggested the presence of influential and outlying points for tibia lead, and the regression results have been provided with and without these subjects.

So that effect modification could be evaluated by ALAD and VDR genotype, cross-product terms of the genetic factors and the lead dose measures were added to the models of the hematopoietic outcomes, one crossproduct term at a time per outcome model. For ALAD genotype, the subjects with $\mathrm{ALAD}^{1-2}$ were compared with subjects with $A L A D^{1-1}$. For VDR genotype, the subjects with VDR BB or Bb were compared with the subjects with VDR bb.

\section{Results}

\section{Demographics and dose measures}

The lead-exposed subjects had a wide range of blood lead, DMSA-chelatable lead, and tibia lead levels (table 1). The corresponding values of the unexposed reference subjects were low. In the crude analysis, hemoglobin (mean of 14.2 versus $15.3 \mathrm{~g} / \mathrm{dl}, \mathrm{P}<0.01$ ) and hematocrit $(42.4 \%$ versus $44.7 \%, \mathrm{P}<0.01)$ levels were significantly lower among the lead-exposed subjects than among the referents without occupational lead exposure; these differences were of relatively small magnitude. In contrast and as expected, the mean levels of ZPP, ALAU, and ALAP were significantly higher among the lead-exposed subjects than among the reference subjects (80.2 versis $38.5 \mu \mathrm{g} / \mathrm{dl}, \mathrm{P}<0.01 ; 2.1$ versus $1.6 \mathrm{mg} / \mathrm{l}$, $\mathrm{P}<0.01$; and 17.7 versus $10.5 \mu \mathrm{g} / \mathrm{ml}, \mathrm{P}<0.01$, respectively) (table 1).

Among the lead workers, $9.9 \%(\mathrm{~N}=79)$ were heterozygous for the $\mathrm{ALAD}^{2}$ allele and $90.1 \%(\mathrm{~N}=716)$ were homozygotes for the $\mathrm{ALAD}^{1}$ allele. For VDR genotype, 
the $\mathrm{Bb}$ or $\mathrm{BB}$ genotypes were identified in $11.2 \%$ $(\mathrm{N}=89)$ of the lead workers, while the bb genotype was identified in $88.8 \%$ ( $\mathrm{N}=709)$. In the crude (unadjusted) analysis, there were no significant differences in the hematopoietic outcomes by ALAD or VDR genotype $(\mathrm{P}>0.05)$ (table 2).

\section{Associations of hematopoietic outcomes with lead biomarkers among the lead-exposed subjects}

Using multiple linear regression to control for covariates, we then compared the three lead biomarkers for their associations with the five hematopoietic outcomes. Tibia lead was the only significant negative predictor of both the hemoglobin and hematocrit levels (table 3), but the additional variance explained by tibia lead was small ( $1 \%$ for hemoglobin, $<1 \%$ for hematocrit). The hemoglobin levels declined $0.0035 \mathrm{~g} / \mathrm{dl}$ per $\mu \mathrm{g} / \mathrm{g}$ of tibia lead, while the hematocrit levels declined $0.01 \%$ per $\mu \mathrm{g} / \mathrm{g}$ of tibia lead. In moving from the 5 th percentile of tibia lead $(3.5 \mu \mathrm{g} / \mathrm{g})$ to the 95 th percentile $(104.2 \mu \mathrm{g} / \mathrm{g})$, the hemoglobin levels would thus be approximately 0.35 $\mathrm{g} / \mathrm{dl}$ lower, and the hematocrit levels would be $1.2 \%$ lower. The addition of blood lead to the regression models for hemoglobin and hematocrit dramatically increased the associations with tibia lead (for hemoglobin, the regression (beta) coefficient changed $37 \%$, from -0.0035 to -0.0048 , and for hematocrit it changed $43 \%$, from -0.0102 to -0.0146$)$. The associations of tibia lead with hemoglobin and hematocrit levels were not dependent on large values of tibia lead (figure 1). An examination of the scatter plots and the smoothed regression lines revealed decreases in hemoglobin and hematocrit levels along the entire range of tibia lead values. In contrast, an examination of the scatter plots and the smoothed regression lines for the relations of blood lead with hemoglobin and hematocrit (figure 2) revealed no clear and consistent relations.

All three lead biomarkers were significantly positive predictors of ZPP, ALAU, and ALAP (table 3). However, an examination of the beta coefficients, modeladjusted $R^{2}$ values and delta $R^{2}$ values (table 3 ), revealed that blood lead was the best predictor of ZPP, while blood lead and DMSA-chelatable lead were similarly associated with ALAU and ALAP. For ZPP (ln-transformed), the additional variance explained was $36 \%$ after the inclusion of blood lead, $33 \%$ after the inclusion

Table 1. Description of the subjects. (ALAP = delta-aminolevulinic acid in plasma, $A L A U=$ delta-aminolevulinic acid in urine, $D M S A=$ dimercaptosuccinic acid, ZPP = zinc protoporphyrin, NA = not applicable)

\begin{tabular}{|c|c|c|c|c|c|c|c|c|c|c|}
\hline \multirow[b]{2}{*}{ Characteristic } & \multicolumn{5}{|c|}{ Lead-exposed subjects $(\mathrm{N}=798)$} & \multicolumn{5}{|c|}{ Unexposed referents $(\mathrm{N}=135)$} \\
\hline & $\mathrm{N}$ & $\%$ & Mean & SD & Range & $\mathrm{N}$ & $\%$ & Mean & SD & Range \\
\hline Age (years) & . & . & 40.5 & 10.1 & $17.8-64.8$ & . & . & 34.5 & 9.1 & $22.0-60.2$ \\
\hline Job duration (years) & $\cdot$ & . & 8.2 & 6.5 & $0.1-36.2$ & . & . & 8.6 & 5.3 & $0.5-30.6$ \\
\hline Height $(\mathrm{cm})$ & . & . & 164.7 & 8.1 & $127.8-186.0$ & . & . & 167.9 & 6.2 & $148.0-183.4$ \\
\hline Weight (kg) & . & . & 62.5 & 9.1 & $37.4-92.7$ & . & . & 66.9 & 9.0 & 48.0-93.5 \\
\hline Body mass index $\left(\mathrm{kg} / \mathrm{m}^{2}\right)$ & $\cdot$ & $\cdot$ & 23.0 & 3.0 & $15.7-34.2$ & $\cdot$ & $\cdot$ & 23.7 & 2.8 & $18.5-30.1$ \\
\hline Sex, Male & 634 & 79.4 & $\cdot$ & $\cdot$ & $\cdot$ & 124 & 91.9 & $\cdot$ & $\cdot$ & $\cdot$ \\
\hline \multicolumn{11}{|l|}{ Tobacco use } \\
\hline $\begin{array}{l}\text { Never } \\
\text { Current use } \\
\text { Past use }\end{array}$ & $\begin{array}{r}254 \\
455 \\
88\end{array}$ & $\begin{array}{l}31.9^{d} \\
57.1 \\
11.0\end{array}$ & $\dot{.}$ & $\begin{array}{l}\cdot \\
\cdot \\
\cdot\end{array}$ & . & $\begin{array}{l}35 \\
87 \\
13\end{array}$ & $\begin{array}{c}25.9 \\
64.4 \\
9.6\end{array}$ & . & $\dot{r}$ & . \\
\hline \multicolumn{11}{|l|}{ Alcohol use } \\
\hline $\begin{array}{l}\text { Never } \\
\text { Current use } \\
\text { Past use }\end{array}$ & $\begin{array}{r}231 \\
518 \\
48\end{array}$ & $\begin{array}{l}29.0^{d} \\
65.0^{-0} \\
6.0\end{array}$ & $\cdot$ & $\cdot$ & $\begin{array}{l}\cdot \\
\cdot \\
\cdot\end{array}$ & $\begin{array}{r}31 \\
95 \\
9\end{array}$ & $\begin{array}{c}23.0 \\
70.4 \\
6.7\end{array}$ & . & $\begin{array}{l}\cdot \\
\cdot \\
\cdot\end{array}$ & . \\
\hline Tibia lead ( $\mu \mathrm{g} \mathrm{Pb/g}$ bone mineral) & $\cdot$ & . & 37.2 & 40.4 & $-7-338$ & $\cdot$ & $\cdot$ & 5.8 & 7.0 & $-11-27$ \\
\hline Blood lead $(\mu \mathrm{g} / \mathrm{dl})^{a}$ & . & . & 32.0 & 15.0 & $4-86$ & . & . & 5.3 & 1.8 & $2-10$ \\
\hline DMSA-chelatable lead $(\mu \mathrm{g})^{b}$ & . & . & 186.0 & 208.4 & $4.8-2103$ & . & . & $N A^{c}$ & $\cdot$ & $\cdot$ \\
\hline Hemoglobin $(g / d l)$ & . & . & 14.2 & 1.4 & $6.5-17.9$ & . & . & 15.3 & 1.2 & $11.1-18.2$ \\
\hline Hematocrit (\%) & $\cdot$ & . & 42.4 & 4.4 & $20.6-58.6$ & . & . & 44.7 & 3.2 & $32.8-53.5$ \\
\hline ZPP ( $\mu \mathrm{g} / \mathrm{dl})$ & $\cdot$ & . & 80.2 & 63.5 & $16-640$ & . & . & 38.5 & 8.5 & 25-69 \\
\hline ALAU (mg/l) & . & . & 2.1 & 3.7 & $0.1-85.8$ & . & . & 1.6 & 0.7 & $0.2-4.4$ \\
\hline $\operatorname{ALAP}(\mu \mathrm{g} / \mathrm{ml})$ & $\cdot$ & . & 17.7 & 20.6 & $2.7-250.6$ & . & . & 10.5 & 2.7 & $4.8-25.4$ \\
\hline
\end{tabular}

a For blood lead, $\mu \mathrm{g} / \mathrm{dl}$ can be converted to $\mu \mathrm{mol} / \mathrm{l}$ by dividing by 20.7 .

b DMSA-chelatable lead $(\mu \mathrm{g})$ was estimated as 4-hour urinary lead excretion after the oral administration of dimercaptosuccinic acid (10mg/kg), for the lead exposed subjects only (784 subjects completed the urine collection)

c The 4-hour urine collection was performed only for subjects who received DMSA. 
of DMSA-chelatable lead, and $10 \%$ after the inclusion of tibia lead. For ALAU (ln-transformed), the additional variance explained was $17 \%, 18 \%$, and $4 \%$, respectively. For ALAP (ln-transformed), the additional variance explained was $29 \%, 29 \%$, and $8 \%$, respectively. An examination of the beta coefficients for blood lead indicated for example (after detransformation from the ln-transformed values) that ZPP, ALAU, and ALAP increased $15.4 \mu \mathrm{g} / \mathrm{dl}, 15.3 \mathrm{mg} / \mathrm{dl}$, and $15.4 \mu \mathrm{g} / \mathrm{ml}$, respectively, for a one standard deviation unit increase in blood lead levels (an increase in blood lead of approximately $15 \mu \mathrm{g} / \mathrm{dl})$.

Table 2. Selected demographic and lead biomarker variables for the 798a lead-exposed subjects. ${ }^{b}(A L A D=$ delta-aminolevulinic acid dehydratase, ALAP = plasma aminolevulinic acid, ALAU = urine aminolevulinic acid, DMSA = dimercaptosuccinic acid, VDR $=$ vitamin D receptor, ZPP = zinc protoporphyrin)

\begin{tabular}{|c|c|c|c|c|c|c|c|c|}
\hline \multirow[b]{3}{*}{ Characteristic } & \multicolumn{4}{|c|}{ ALAD genotype } & \multicolumn{4}{|c|}{ VDR genotype } \\
\hline & \multicolumn{2}{|c|}{$1-1$} & \multicolumn{2}{|c|}{$1-2$} & \multicolumn{2}{|c|}{$b b$} & \multicolumn{2}{|c|}{$\mathrm{Bb}$ or $\mathrm{BB}$} \\
\hline & Mean & SD & Mean & SD & Mean & SD & Mean & SD \\
\hline Age (years) & 40.5 & 10.2 & 40.1 & 9.7 & 40.2 & $10.0^{*}$ & 42.7 & $10.3^{*}$ \\
\hline Job duration (years) & 8.2 & 6.6 & 8.2 & 5.8 & 8.4 & 6.6 & 7.2 & 5.6 \\
\hline Hemoglobin (g/dl) & 14.2 & 1.4 & 14.2 & 1.6 & 14.2 & 1.4 & 14.1 & 1.4 \\
\hline Hematocrit (\%) & 42.4 & 4.4 & 42.4 & 4.9 & 42.4 & 4.4 & 42.6 & 4.8 \\
\hline ZPP $(\mu \mathrm{g} / \mathrm{dl})$ & 80.1 & 61.7 & 81.6 & 78.6 & 79.5 & 63.2 & 86.2 & 66.5 \\
\hline ALAU (mg/l) & 2.0 & 2.2 & 3.2 & 9.9 & 2.1 & 3.9 & 2.1 & 1.8 \\
\hline $\operatorname{ALAP}(\mu \mathrm{g} / \mathrm{ml})$ & 17.5 & 18.9 & 19.8 & 32.0 & 17.4 & 20.0 & 20.0 & 25.0 \\
\hline Blood lead $(\mu \mathrm{g} / \mathrm{dl})^{\mathrm{c}}$ & 31.7 & 14.9 & 34.2 & 15.9 & 31.6 & 14.8 & 34.8 & 16.1 \\
\hline Tibia lead $(\mu \mathrm{g} / \mathrm{g})$ & 37.5 & 40.6 & 31.4 & 29.5 & 37.1 & 41.2 & 38.1 & 33.5 \\
\hline DMSA-chelatable lead $(\mu \mathrm{g})$ & 180.3 & 181.2 & 161.7 & 143.0 & 173.5 & $176.8^{*}$ & 217.2 & $179.7^{\star}$ \\
\hline
\end{tabular}

${ }^{a} \mathrm{ALAD}$ and VDR genotyping was completed on 798 and 795 lead workers, respectively.

b Number and percent (in parentheses): 716 (90.1) for the 1-1 ALAD genotype, 79 (9.9), for the 1-2 ALAD genotype, 709 (89.3), for the bb VDR genotype, 89 (10.7), for the Bb or BB VDR genotype.

c For blood lead, $\mu \mathrm{g} / \mathrm{dl}$ can be converted to $\mu \mathrm{mol} / \mathrm{l}$ by dividing by 20.7 .

${ }^{*} \mathrm{P}<0.05$.

Table 3. Linear regression modeling a the hematopoietic outcomes for the Korean lead workers of this study, 1997-1999. (ALAD = delta-aminolevulinic acid dehydratase , ALAP = delta-aminolevulinic acid in plasma, ALAU = delta-aminolevulinic acid in urine, DMSA = dimercaptosuccinic acid, VDR = vitamin D receptor, ZPP = zinc protoporphyrin)

\begin{tabular}{|c|c|c|c|c|}
\hline Lead variable & Beta & Standard error of the beta & P-value & Model adjusted $\mathrm{R}^{2}$ \\
\hline \multicolumn{5}{|l|}{ Hemoglobin $(g / d l)$ models } \\
\hline Blood lead (g/dl per $\mu \mathrm{g} / \mathrm{dl})$ & 0.0032 & 0.0031 & 0.30 & 0.39 \\
\hline DMSA-lead (g/dl per $\mu \mathrm{g})$ & -0.0003 & 0.0002 & 0.25 & 0.40 \\
\hline Tibia lead $(\mathrm{g} / \mathrm{dl}$ per $\mu \mathrm{g} / \mathrm{g})$ & -0.0035 & 0.0011 & $<0.01$ & 0.40 \\
\hline \multicolumn{5}{|c|}{ Hematocrit (\%) models (15 highest values excluded, $>52 \%$ ) } \\
\hline Blood lead $(\%$ per $\mu \mathrm{g} / \mathrm{dl})$ & 0.0125 & 0.0093 & 0.18 & 0.37 \\
\hline DMSA-lead $(\%$ per $\mu \mathrm{g})$ & 0.0001 & 0.0008 & 0.94 & 0.37 \\
\hline Tibia lead $(\%$ per $\mu \mathrm{g} / \mathrm{g})$ & -0.0102 & 0.0034 & $<0.01$ & 0.37 \\
\hline \multicolumn{5}{|c|}{ ZPP $[\ln (\mu \mathrm{g} / \mathrm{dl})]$ models (In-transformed) } \\
\hline Blood lead [ln( $\mu \mathrm{g} / \mathrm{dl})$ per $\mu \mathrm{g} / \mathrm{dl}]$ & 0.0251 & 0.0011 & $<0.01$ & 0.46 \\
\hline DMSA-lead [In( $\mu \mathrm{g} / \mathrm{dl})$ per $\mu \mathrm{g}]$ & 0.0019 & 0.0001 & $<0.01$ & 0.43 \\
\hline Tibia lead $[\ln (\mu \mathrm{g} / \mathrm{dl})$ per $\mu \mathrm{g} / \mathrm{g}]$ & 0.0048 & 0.0005 & $<0.01$ & 0.20 \\
\hline \multicolumn{5}{|c|}{ ALAU [In(mg/l)] models (In-transformed) } \\
\hline Blood lead [ln(mg/l) per $\mu \mathrm{g} / \mathrm{dl}]$ & 0.0219 & 0.0017 & $<0.01$ & 0.21 \\
\hline DMSA-lead [In(mg/l) per $\mu \mathrm{g}]$ & 0.0018 & 0.0001 & $<0.01$ & 0.22 \\
\hline Tibia lead $[\ln (\mathrm{mg} / \mathrm{l})$ per $\mu \mathrm{g} / \mathrm{g}]$ & 0.0036 & 0.0007 & $<0.01$ & 0.08 \\
\hline \multicolumn{5}{|c|}{ ALAP [In( $\mu \mathrm{g} / \mathrm{ml})]$ models (In-transformed) } \\
\hline Blood lead $[\ln (\mu \mathrm{g} / \mathrm{ml})$ per $\mu \mathrm{g} / \mathrm{dl}]$ & 0.0235 & 0.0012 & $<0.01$ & 0.38 \\
\hline DMSA-lead $[\ln (\mu \mathrm{g} / \mathrm{ml})$ per $\mu \mathrm{g}]$ & 0.0018 & 0.0001 & $<0.01$ & 0.38 \\
\hline Tibia lead $[\ln (\mu \mathrm{g} / \mathrm{ml})$ per $\mu \mathrm{g} / \mathrm{g}]$ & 0.0044 & 0.0005 & $<0.01$ & 0.17 \\
\hline
\end{tabular}

a Blood lead, DMSA-chelatable lead, and tibia lead were all included separately in each hematopoietic outcome model. Models were controlled for age, gender, body mass index (for hemoglobin and hematocrit only), work duration, categories of lifetime tobacco consumption, categories of lifetime alcohol consumption, and ALAD and VDR genotype. 

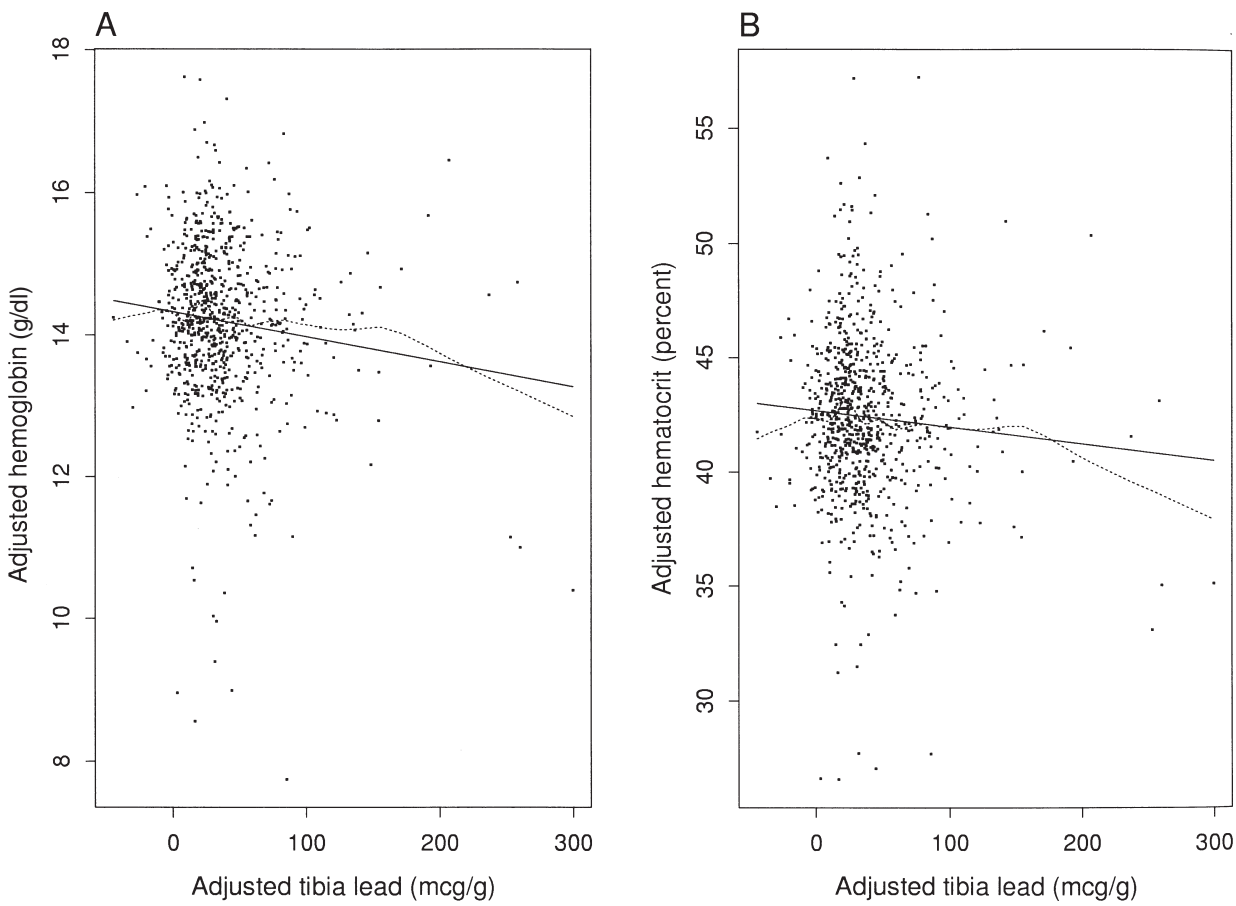

Figure 1. Associations (residual versus residual plots) of tibia lead with the hemoglobin (A) and hematocrit (B) values of the lead workers, after adjustment for age, gender, body mass index, work duration, categories of lifetime tobacco consumption, categories of lifetime alcohol consumption, and delta-aminolevulinic acid dehydratase (ALAD) and vitamin D receptor (VDR) genotype. The solid lines are from the linear regression models. The dotted lines were estimated by a smoothing method (45) using the S-PLUS statistical software function lowess, and they were adjusted for the covariates. For ease of interpretation, the axes have been scaled so that the plotted residuals are centered around the mean tibia lead value, rather than around zero.
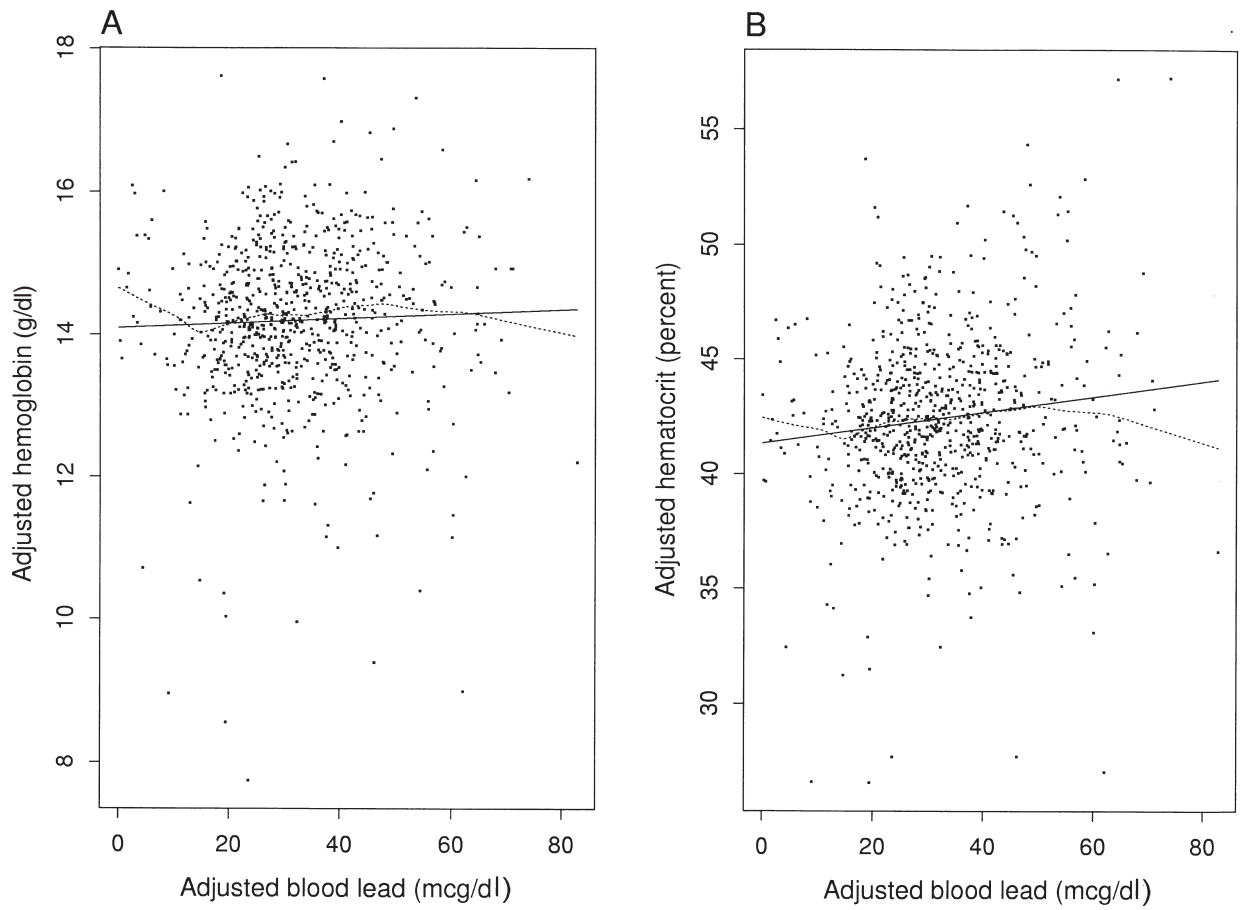

Figure 2. Associations (residual versus residual plots) of blood lead values with the hemoglobin (A) and hematocrit (B) values of the lead workers after adjustment for age, gender, body mass index, work duration, categories of lifetime tobacco consumption, categories of lifetime alcohol consumption, and delta-aminolevulinic acid dehydratase (ALAD) and vitamin D receptor (VDR) genotype. The solid lines are from the linear regression models. The dotted lines were estimated by a smoothing method (45) using the S-PLUS statistical software function lowess, and they were adjusted for the covariates. For ease of interpretation, the axes have been scaled so that the plotted residuals are centered around the mean blood lead value, rather than around zero. 


\section{Associations of hematopoietic outcomes with ALAD and VDR genotypes in lead-exposed subjects}

On the average, the lead workers with the VDR "B" allele (BB or Bb genotypes) had higher hematocrit levels than the lead workers with the VDR bb genotype. For example, in the model with tibia lead (table 3 ), the mean hematocrit was $0.77 \%$ higher $(\mathrm{P}=0.06)$. An examination of the residual-residual plots indicated that the association between VDR genotype and hematocrit was dependent on the eight subjects with the highest tibia lead levels. ALAD genotype was associated with the ZPP levels in the model with blood lead (lnZPP levels being $0.0979 \ln (\mu \mathrm{g} / \mathrm{dl})$ lower [equivalent to $10 \%$ lower] in subjects with the $A L A D^{1-2}$ genotype $\left.[\mathrm{P}=0.05]\right)$, but not after control for tibia lead or DMSA-chelatable lead, a finding suggesting that the association between ALAD genotype and ZPP may have been mediated through the blood lead levels. VDR and ALAD genotypes were not associated with any of the other hematopoietic measures.

Next, we evaluated the effect modification by ALAD and VDR genotypes on the relations between the three lead biomarkers and five hematopoietic outcomes with the inclusion of the interaction terms. For interactions between the lead biomarkers and ALAD genotype, 3 of the 15 interaction terms (for InALAU, ALAD · blood lead and ALAD-tibia lead, and for InALAP, ALAD - tibia lead) were significantly associated $(\mathrm{P}<0.05)$ and one other (for lnALAP, ALAD · blood lead) was marginally associated $(\mathrm{P}=0.06)$ with the hematopoietic outcomes. The coefficients for all four of these interaction terms were positive, the finding indicating a steeper slope (more of an effect) for the relation of the lead biomarker with ALAU or ALAP for the subjects with the $\mathrm{ALAD}^{2}$ allele. An examination of the residual-residual plots and additional regressions without outlying values indicated that the statistical significance of these interaction terms was highly dependent on the nine subjects with the highest blood lead levels (the highest $1 \%$ of the study population). After these subjects were excluded, the effect modification by ALAD genotype was no longer observed. However, after the exclusion of these nine subjects, a main effect of ALAD genotype was observed for ALAP (after detransformation, the mean ALAP was 9\% lower for the subjects with $\mathrm{ALAD}^{2}$ when compared with homozygotes for $\left.\mathrm{ALAD}^{1}, \mathrm{P}=0.04\right)$.

For interactions between the lead biomarkers and VDR genotype, one of the 15 interaction terms (for hematocrit, VDR · tibia lead) was significantly associated, and two others (for hemoglobin, VDR · blood lead and VDR - tibia lead) were marginally associated with the hematopoietic outcomes. The coefficients for all three of these interaction terms were positive, the finding in- dicating a weaker relation of the lead biomarker with hemoglobin or hematocrit for the subjects with the VDR $B$ allele. An examination of the residual-residual plots indicated that the effect modification by VDR genotype on the relations of tibia lead with hemoglobin and hematocrit were heavily influenced by the eight subjects with the highest tibia lead levels. When these subjects were eliminated from the regression models of these two outcome measures, the effect modification was no longer apparent.

\section{Discussion}

We compared and contrasted the associations of three different lead biomarkers (blood lead, DMSA-chelatable lead, and tibia lead) with five hematopoietic outcomes in a large cross-sectional study of Korean lead workers. All three lead biomarkers were significantly associated with ZPP, ALAU, and ALAP, but blood lead was generally the best predictor of each of these measures, based on a comparison of beta coefficients, total model-adjusted $\mathrm{R}^{2}$ values, and delta $\mathrm{R}^{2}$ values. Blood lead and DMSA-chelatable lead were highly correlated (Pearson's correlation coefficient $=0.81$ with untransformed DMSA-chelatable lead and 0.87 after ln-transformation); therefore the associations with chelatable lead were similar to those with blood lead. In contrast, only tibia lead was significantly associated with the hemoglobin and hematocrit levels, with or without control for the blood lead levels in the same models. These contrasting associations illustrate the importance of evaluating several lead dose measures in studies of the health effects of lead, as the measures may be differentially relevant to acute and chronic effects and the role of recent and cumulative exposures.

ALAU, ALAP, and ZPP have long been recognized to be early biological effects of lead exposure and have been used in health effects monitoring for lead exposure $(3,39-42)$. It is known that these measures increase in the presence of lead exposure and then decline after lead levels decline. For erythrocytes, heme synthesis occurs in erythroid cells in the bone marrow. Circulating erythrocytes survive for approximately 120 days, and this 120-day life span of red cells influences the kinetics of both ZPP and blood lead levels. Blood lead was the best predictor of the ZPP, ALAU, and ALAP levels, and this finding suggests that blood lead levels are the best estimate of the lead levels in the bone marrow to which ALAD and ferrochelatase are exposed. It is thought that plasma lead is the most relevant to health because it is the main circulatory compartment of lead that has access to cell membranes and can deposit in 
critical target organs. It is known that blood lead level is the most important predictor of plasma lead level, accounting for $90-95 \%$ of the variability in plasma lead $(44,44)$. The vast majority of blood lead is associated with erythrocytes with only a small proportion, 1-3\%, in plasma.

In prior studies, blood lead levels have not been a good predictor of hemoglobin levels. For example, Froom et al (18) reported that hemoglobin levels did not correlate with blood lead, and they concluded that periodic hemoglobin determinations were not a useful indicator of lead exposure. In the current study, blood lead was also not a predictor of hemoglobin levels, but tibia lead was a significant predictor of both the hemoglobin and hematocrit levels, a finding consistent with the results of one prior study (19). Hu et al (19) reported that patella lead was associated with lower levels of hemoglobin and hematocrit, while blood lead levels were not. The authors concluded that patella lead may serve as a surrogate for kidney lead burden, where erythropoietin synthesis occurs, and its association with hemoglobin and hematocrit levels may be explained through the depression of erythropoietin synthesis (19).

In our study, tibia lead, a measure of the lifetime dose of lead, was a predictor of the hemoglobin and hematocrit levels, while neither blood lead, an estimate of integrated exposure to internal and external sources of lead over the past 4 months, nor DMSA-chelatable lead, an estimate of soft tissue lead levels (28), were predictors. These observations suggest that lead must have a chronic, cumulative effect on hemoglobin and hematocrit levels, possibly mediated through the kidney, and any speculated mechanism cannot merely involve shortterm plasma or target organ lead levels. In fact, we observed stronger associations for tibia lead with hemoglobin and hematocrit after control for blood lead, a finding supporting the notion that chronic, cumulative effects may be more readily observed after adjustment for possible short-term effects. It should be noted, however, that the saturation of lead-binding sites in erythrocytes could lead to nonlinear relations of blood lead with health outcomes, the associations that may be observed in linear regression modeling being obscured.

In our study, ALAD genotype did not appear to modify relations between the lead biomarkers and hemoglobin, hematocrit, or ZPP. It is possible that ALAD genotype modified the effect of the relations of blood lead with ALAP and ALAU in the subjects with the highest blood lead levels, but, as these relations were dependent on only the nine highest blood lead levels, we cannot be certain. Rather, ALAD genotype appeared to exert a main effect on the relations of blood lead with ZPP and ALAP. For both outcomes, the mean levels were approximately $10 \%$ lower in the subjects with $\mathrm{ALAD}^{2}$, independent of the blood lead levels. Prior studies have observed both main effects and effect modification by ALAD genotype with hematopoietic outcomes. Sakai et al (45) reported higher ALAP and ZPP levels for subjects with $\mathrm{ALAD}^{1}$ who had blood lead levels over 40 $\mu \mathrm{g} / \mathrm{dl}$ and $20 \mu \mathrm{g} / \mathrm{dl}$, respectively, without differences in ALAD activity by genotype. Alexander et al (12) reported effect modification by ALAD genotype on the relation between blood lead and ZPP levels, with a larger slope for subjects with $\mathrm{ALAD}^{1}$. Sithisarankul et al (8) reported that subjects with $\mathrm{ALAD}^{1}$ had higher ALAP levels without evidence of effect modification. The observation of independent associations between blood lead and ALAD genotype with the hematopoietic outcomes, without clear evidence of effect modification, would suggest that lead does not exert its influence on ZPP and ALAP levels via the ALAD protein products.

To our knowledge, no prior studies have evaluated the relations of VDR genotype with hematopoietic outcomes. In our study, controlling for tibia lead levels, the subjects with the VDR B allele had higher hematocrit levels than did those with the VDR bb genotype $(\mathrm{P}=0.06)$. This relation was not apparent when blood lead was included in the model instead of tibia lead. There was no clear effect modification by VDR genotype on the relations between the tibia lead levels and hemoglobin and hematocrit, as the relations were not observed after the elimination of the eight subjects with the highest tibia lead levels.

In conclusion, blood lead was the best predictor of the ZPP, ALAU, and ALAP levels, and tibia lead was the best predictor of hemoglobin and hematocrit. ALAD and VDR genotypes are known to influence the toxicokinetics of lead. Studies have documented differences in blood lead, DMSA-chelatable lead, tibia lead, and patella lead by these two genes. To date, the influence of these two genes on the relations between lead and health measures have provided somewhat inconsistent evidence of main effects and effect modification. For the hematopoietic outcomes, the $\mathrm{ALAD}^{2}$ allele appears to be associated with lower ZPP and ALAP levels independently of lead, but ALAD genotype did not clearly modify the associations between the lead biomarkers and the hematopoietic outcomes. The VDR B allele may have been associated with higher hematocrit levels, but it did not clearly modify the associations between the lead biomarkers and the hematopoietic outcomes.

\section{Acknowledgments}

We wish to thank Dr Patrick J Parsons for performing the urine lead measurements and Drs Yong-Bae Kim, Kyu-Yoon Hwang, and Kyu-Dong Ahn for assisting in the data collection in Korea.

Scand J Work Environ Health 2001, vol 27, no 6 
This research was supported by grants ES07198 (Dr Schwartz) and ES00002 (Dr Kelsey) from the National Institute of Environmental Health Sciences and, in part, by grant HMP-97-M-4-0047 from the Ministry of Health and Welfare, Republic of Korea. This publication was also made possible by grant number 2 P42 ES-05947 from the National Institute of Environmental Health Sciences with funding provided by the Environmental Protection Agency. Its contents are solely the responsibility of the authors and do not necessarily represent the official views of the National Institute of Environmental Health Sciences, National Institutes of Health, or the Environmental Protection Agency.

\section{References}

1. Rossi E, Taketani S, Garcia-Webb P. Lead and the terminal mitochondrial enzymes of haem biosynthesis. Biomed Chromatogr 1993;7:1-6.

2. Goyer RA, Rhyne B. Pathological effects of lead. Int Rev Exp Pathol 1973;12:1-77.

3. Environmental Protection Agency. Air quality criteria for lead. Research Triangle Park (NC): US Environmental Protection Agency, Office of Research and Development, 1986.

4. Agency for Toxic Substances and Disease Registry. Toxicological profile for lead. Atlanta (Ga): US Department of Health and Human Services, 1993.

5. Granick S, Mauzerall D. Porphyrin biosynthesis in erythrocytes, II: enzyme converting $\delta$-aminolevulinic acid to coproporphyrinogen. J Biol Chem 1958;232:1119-40.

6. Bernard A, Lauwerys R. Metal-induced alterations of $\delta$-aminolevulinic acid dehydratase. Ann NY Acad Sci 1987;514: 41-7.

7. Sakai T, Morita Y. $\delta$-aminolevulinic acid in plasma or whole blood as a sensitive indicator of lead effects, and its relation to other heme-related parameters. Int Arch Occup Environ Health 1996;68:126-32.

8. Sithisarankul P, Schwartz BS, Lee B-K, Kelsey KT, Strickland PT. Aminolevulinic acid dehydratase genotype mediates plasma levels of the neurotoxin, 5-aminolevulinic acid, in lead-exposed workers. Am J Ind Med 1997;32:15-20.

9. Taketani S, Tanaka A, Tikunaga R. Reconstitution of hemesynthesizing activity from ferric iron and porphyrins, and the effect of lead on the activity. Arch Biochem Biophys 1985;242:291-6.

10. Marcus AH, Schwartz J. Dose-response curves for erythrocyte protoporphyrin vs blood lead: effects of iron status. Environ Res 1987;44:221-7.

11. Piomelli S. Chemical toxicity of red cells. Environ Health Perspect 1981;39:65-70.

12. Alexander BH, Checkoway H, Costa-Mallen P, Faustman EM, Woods JS, Kelsey KT, et al. Interaction of blood lead and -aminolevulinic acid dehydratase genotype on markers of heme synthesis and sperm production in lead smelter workers. Environ Health Perspect 1998;106:213-6.

13. Bashir R, Khan DA, Saleem M, Zaman KU, Malik IA. Blood lead levels and anemia in lead exposed workers. J Pak Med Assoc 1995;45:64-6.

14. Poulos S, Qammaz S, Athanaselis S, Maravelias C, Kout- selinis A. Statistically significant hematopoietic effects of low blood lead levels. Arch Environ Health 1986;41:384-6.

15. Piomelli S, Seaman C, Zullow D, Curran A, Davidow B. Threshold for lead damage to heme synthesis in urban children. Proc Natl Acad Sci USA 1982;79:3335-9.

16. Schwartz J, Landrigan PJ, Baker EL Jr, Orenstein WA, von Linderin IH. Lead-induced anemia: dose-response relationships and evidence for a threshold. Am J Public Health 1990;80:165-8.

17. Valentine JL, Baloh RW, Browdy BL, Gonick HC, Brown $\mathrm{CP}$, Spivey GH, et al. Subclinical effects of chronic increased lead absorption: a prospective study. Part IV. Evaluation of heme synthesis effects. J Occup Med 1982;24:120-5.

18. Froom P, Kristal-Boneh E, Benbassat J, Ashkanazi R, Ribak J. Lead exposure in battery-factory workers is not associated with anemia. J Occup Environ Med 1999;41:120-3.

19. Hu H, Watanabe H, Payton M, Korrick S, Rotnitzky A. The realtionship between bone lead and hemoglobin. J Am Med Assoc 1994;272:1512-7.

20. Schwartz BS, Lee B-K, Stewart W, Ahn K-D, Kelsey KT. $\delta$ Aminolevulinic acid dehydratase genotype modifies 4-hour urinary lead excretion after oral administration of dimercaptosuccinic acid. Occup Environ Med 1997;54:241-6.

21. Schwartz BS, Lee B-K, Lee G-S, Stewart WF, Lee S-S, Hwang K-Y, et al. Associations of blood lead, dimercaptosuccinic acid-chelatable lead, and tibia lead with neurobehavioral test scores in South Korean lead workers. Am J Epidemiol 2001;153:453-64.

22. Schwartz BS, Lee B-K, Lee G-S, Stewart WF, Simon D, Kelsey K, et al. Associations of blood lead, DMSA-chelatable lead, and tibia lead with polymorphisms in the vitamin D receptor and $\delta$-aminolevulinic acid dehydratase genes. Environ Health Perspect 2000;108:949-54.

23. Todd AC, Lee B-K, Lee G-S, Ahn K-D, Schwartz BS. Predictors of blood lead, tibia lead, and DMSA-chelatable lead in 802 Korean lead workers. Occup Environ Med 2001;58:73-80.

24. Todd AC, Carroll S, Godbold JH, Moshier EL, Khan FA. Variability in XRF-measured tibia lead levels. Phys Med Biol 2000;45:3737-48.

25. Todd AC, McNeill FE, Palethorpe JE, Peach DE, Chettle DR, Tobin MJ, et al. In vivo X-ray fluorescence of lead in bone using K X-ray excitation with ${ }^{109} \mathrm{Cd}$ sources: radiation dosimetry studies. Environ Res 1992;57:117-32.

26. Todd AC, McNeill FE. In vivo measurements of lead in bone using a Cd spot source. In: Human body composition studies. New York (NY): Plenum Press, 1993:299-302.

27. Kneip TJ, Crable JV. Methods for biological monitoring: a manual for assessing human exposure to hazardous substances. Washington (DC): American Public Health Association, 1988:199-201.

28. Lee B-K, Schwartz BS, Stewart W, Ahn K-D. Urinary lead excretion after DMSA and EDTA: evidence for differential access to lead store sites. Occup Environ Med 1995;52:13-9.

29. Parsons PJ, Slavin W. Electrothermal atomization atomic absorption spectrometry for the determination of lead in urine: results of an interlaboratory study. Spectrochim Acta Part B 1999;54:853-64.

30. Thomas WJ, Collins TM. Comparison of venipuncture blood counts with microcapillary measurements in screening for anemia in one-year-old infant. J Pediatr 1982;101:32-5.

31. Blumberg WE, Eisinger J, Lamola AA, Zuckerman DM. Zinc protoporphyrin level in blood determination by a portable hematofluorometer: a screening device for lead poison- 
ing. J Lab Clin Med 1977;89:712-23.

32. Tomokuni K, Ichiba M, Hirai Y. Measurement of urinary $\delta$ Aminolevulinic acid (ALA) by fluorometric HPLC and colorimetric methods. Ind Health 1992;30:119-28.

33. Heinegard D, Tiderstrom G. Determination of serum creatinine by a direct colorimetric method. Clin Chim Acta 1973;43:305-10.

34. Schwartz BS, Stewart WF, Kelsey KT, Simon D, Park S, Links JM, et al. Associations of tibial lead levels with Bsm I polymorphisms in the vitamin $\mathrm{D}$ receptor in former organolead manufacturing workers. Environ Health Perspect 2000;108:199-203.

35. Schwartz BS, Lee B-K, Stewart W, Ahn K-D, Springer K, Kelsey K. Associations of $\delta$-aminolevulinic acid dehydratase genotype with plant, exposure duration, and blood lead and zinc protoporphyrin levels in Korean lead workers. Am J Epidemiol 1995;142:738-45.

36. Wetmur JG, Lehnert G, Desnick RJ. The $\delta$-aminolevulinate dehydratase polymorphism: higher blood lead levels in lead workers and environmentally exposed children with the 1-2 and 2-2 isozymes. Environ Res 1991;56:109-19.

37. Ziemsen B, Angerer J, Lehnert G, Benkmann HG, Goedde HW. Polymorphism of delta-aminolevulinic acid dehydratase in lead-exposed workers. Int Arch Occup Environ Health. 1986;58:245-7.

38. Cleveland WS. Robust locally weighted regression and smoothing scatter plots. J Am Stat Assoc 1979;74:829-36.
39. Centers for Disease Control (CDC). Prevention of lead poisoning in young children. Atlanta (GA): Department of Health and Human Services, Public Health Services, 1991.

40. Hammond PB, Bornschein RL, Succop P. Dose-effect and dose-response relationship of blood lead to erythrocytic protoporphyrin in young children. Environ Res 1985;38:18796.

41. Lilis R, Eisinger J, Blumberg W, Fischbein A, Selikoff IJ. Hemoglobin, serum iron, and zinc protoporphyrin in leadexposed workers. Environ Health Perspect 1978;25:97-102.

42. Wildt K, Berlin M, Isberg PE. Monitoring of zinc protoporphyrin levels in blood following occupational lead exposure. Am J Ind Med 1987;12:385-98.

43. Hernandez-Avila M, Smith D, Meneses F, Sanin LH, Hu U. The influence of bone and blood lead on plasma levels in environmentally exposed adults. Environ Health Perspect 1998;106:473-7.

44. Bergdahl IA, Skerfving S. Partition of circulating lead between plasma and red cells does not seem to be different for internal and external sources of lead. Am J Ind Med 1997;32:317-8.

45. Sakai T, Morita Y, Araki T, Kano M, Yoshida T. Relationship between delta-aminolevulinic acid dehydratase genotypes and heme precursors in lead workers. Am J Ind Med 2000;38:355-60.

Received for publication: 12 February 2001 